\title{
Turismo de base comunitária: uma experiência na Zona de Educação para o Ecodesenvolvimento do Rio Sagrado (Morretes, Paraná, Brasil)
}

\section{Community-based tourism: an experience in the area of education for eco- development of the Rio Sagrado (Morretes, Paraná, Brazil)}

\author{
Liliane Cristine Schlemer Alcântara (ALCÂNTARA, L. C. S.) ${ }^{*}$ \\ Shimene Feuser (FEUSER, S.) ${ }^{* * *}$ \\ Carlos Alberto Cioce Sampaio (SAMPAIO, A. C. C.) ${ }^{* * *}$
}

\begin{abstract}
RESUMO - Frente às inovações tecnológicas e mudanças na organização de trabalho no meio rural, priorizou-se um modelo de desenvolvimento que privilegiasse a conservação da cultura rural, mais solidária, inclusiva e a preservação da biodiversidade. Neste sentido, o objetivo deste artigo está em analisar a contribuição do turismo de base comunitária na preservação da identidade cultural na Zona de Educação para o Ecodesenvolvimento da Microbacia Hidrográfica do Rio Sagrado, em Morretes (Paraná, Brasil). A abordagem metodológica resulta de um esforço de pesquisa-ação realizado entre 2006 e 2012 junto a Zona Laboratório de Educação para o Ecodesenvolvimento na Microbacia do Rio Sagrado. Percebeu-se que o turismo de base comunitária se apresentava como uma estratégia de sobrevivência e de conservação dos modos de vida e da biodiversidade, oportunizando às pequenas comunidades geração de renda e desenvolvimento local. Além disso, possibilitando o bem estar comum e garantindo a sobrevivência de seus membros, preservando sua identidade cultural.
\end{abstract}

\footnotetext{
* Formação: Graduação em Administração pela Sociedade Educacional Três de Maio (SETREM/RS), Mestrado em Administração (FAESP/SP), Doutoranda do Programa de Pós-graduação em Desenvolvimento Regional (PPGDR) da Universidade Regional de Blumenau (FURB) com sandwich em Mondragon Unibertsitatea (MU) - Facultad de Humanidades y Ciencias de la Educación (HUHEZI) (Espanha). Pesquisadora do Núcleo de Pesquisas Públicas (NPP). Bolsista da Coordenação de Aperfeiçoamento de Pessoal de Nível Superior- CAPES - Processo N. 381/2014-04. Pesquisadora do Conselho Nacional de Desenvolvimento Científico e Tecnológico - CNPq: chamada MCTI/CNPq/MEC/CAPES No 43/2013. Professora da Universidade Federal de São Carlos (UFSCar). Endereço físico para correspondência: Avenida um, 411, ap. 52 (Centro). CEP 13500-401 - Rio Claro/SP - Brasil. Email: lilianecsa@yahoo.com.br

*** Formação: Graduação em Engenharia Florestal pela Universidade Regional de Blumenau (FURB/SC), Mestrado em Desenvolvimento Regional (FURB/SC), Doutoranda do Programa de Pós-graduação em Desenvolvimento Regional (PPGDR) da Universidade Regional de Blumenau (FURB). Pesquisadora do Núcleo de Pesquisas Públicas (NPP). Bolsista da Coordenação de Aperfeiçoamento de Pessoal de Nível Superior (CAPES). Endereço físico para correspondência: Rua Antônio da Veiga, 140 (Victor Konder). CEP 89030-903 - Blumenau/SC - Brasil. Email: eng.shimene@ gmailcom

*** Formação: Graduação em Administração pela Pontifícia Universidade Católica de São Paulo, Mestrado em Administração pela Universidade Federal de Santa Catarina (UFSC), Doutorado em Engenharia de Produção pela UFSC com sandwich em Economia Social pela École dês Hautes Études en Sciences Sociales, França. Pós-Doutor em Ciências Ambientais pela Washington State School, USA, em Cooperativismo Corporativo pela Univesidad de Mondragón, Espanha, e em Ecossoecionomia pela Universidad Austral de Chile. Professor dos Programas de Pós-Graduação (PPG) em Gestão Urbana/PUCPR, em Desenvolvimento Regional/FURB e em Meio Ambiente e Desenvolvimento/UFPR. Colaborador do Programa em Turismo/UFPR. Visitante do PPG em Desenvolvimento à Escala Humana e Economia Ecológica/UACh. Pesquisador CNPq. Coordenador Adjunto da Área em Ciências Ambientais/CAPES. Endereço para correspondência: Rua Vereador Washington Mansur, 248 ap. 61 (Ahú). CEP: 80.540-210 - Curitiba/PR - Brasil. Email: carlos.cioce@ gmail.com
} 
Palavras-chave: Turismo de base comunitária; Zona de educação para o ecodesenvolvimento; Identidade cultural.

ABSTRACT - Faced with technological innovations and changes in the organization of work in rural areas, it is prioritized a model of development that promotes the preservation of rural culture, more equitable, inclusive and the preservation of biodiversity. In this sense, the purpose of this article is to analyze the contribution of community-based tourism in the preservation of cultural identity in the Educational Zone for Eco-Development of Watershed Hydrographic Rio Sagrado in Morretes (Paraná). The methodological approach is the result of an effort from action research conducted between 2006 and 2013 at the Laboratory Zone Education for EcoDevelopment in the Sacred River Watershed. It was noticed that the community-based tourism is presented as a strategy for survival and preservation of livelihoods and biodiversity, providing opportunities to small communities generate income and local development. Common also enables the welfare and ensures the survival of its members, preserving their cultural identity.

Key words: Community-based tourism; Education for eco-development zone; Cultural identity. 


\section{INTRODUÇÃO}

O meio rural está passando por grandes transformações, principalmente no que diz respeito às relações de produção e busca de novas fontes de trabalho e renda que gerem a dinamização sustentável dos territórios. Neste sentido, o turismo de base comunitária desenvolvido nas propriedades familiares contribui para a revitalização do mundo rural, seus significados e para a preservação do ambiente natural.

[...] a sociedade vem descobrindo a importância ambiental e o valor estratégico de manutenção da paisagem rural, e passa a tratar rios, fauna e flora como elementos essenciais para o ser humano. Este contexto tem propiciado a revalorização do modo de vida e o surgimento de novas funções econômicas, sociais e ambientais para o espaço rural, permitindo ao agricultor novas maneiras de garantir sua permanência no campo (BRASIL, 2010a, p. 13).

Aliando-se a esse contexto, o turismo de base comunitária, além de geração de trabalho e renda, contribui para a revitalização econômica e social, na valorização do patrimônio e da cultura local, conservação do meio ambiente e atração de investimentos públicos nos locais em que esteja sendo desenvolvido (BRASIL, 2010b). Tem como atrativo contemplar aspectos culturais "[...] por meio do resgate das manifestações e práticas regionais (como folclore, trabalhos manuais, costumes, ofícios, festas, "causos", culinária), e primar pela conservação do ambiente natural, paisagem e cultura (artesanato, música e arquitetura)” (BRASIL, 2010b, p. 21).

Quando se refere aos aspectos das sociedades que são aprendidos e não herdados, reporta-se à definição de que as manifestações e práticas regionais "[...] são partilhados pelos membros da sociedade e tornam possível a cooperação e a comunicação. Eles formam o contexto comum em que os indivíduos de uma sociedade vivem as suas vidas" (GIDDENS, 2004, p. 22). Conforme o autor, a cultura engloba tanto os aspectos intangíveis - crenças, ideias e gastronomia - como os aspectos tangíveis - artefatos, símbolos e tecnologia. A cultura é conjunto de elementos que compreendem aspectos da vida dos povos, como: idioma, interações sociais, religião, educação e demais sistemas de valores.

O padrão de cultura pode ser definido como significados incorporados nas formas simbólicas, que inclui ações, manifestações verbais e objetos significativos de vários tipos, em virtude dos quais os indivíduos comunicamse entre si e partilham suas experiências, concepções e crenças (THOMPSON, 1995, p. 176). 
Neste contexto a identidade cultural, como sistema de representação das relações entre indivíduos e grupos é um processo dinâmico, de construção continuada, que se retroalimenta a partir do vetor espaço-tempo, tendo como objetivo à preservação do patrimônio local com suas características e peculiaridades próprias (OLIVEIRA, 2015). No seu conjunto, surgem as prerrogativas para pensar o turismo de base comunitária.

A abordagem metodológica deste artigo extraiu-se de um esforço de pesquisaação realizado entre 2006 e 2012, junto a Zona de Educação para o Ecodesenvolvimento na Microbacia do Rio Sagrado, Comunidades do Rio Sagrado de Cima, Canhembora, Brejumirim e Candonga (distrito do município de Morreste, Paraná, Brasil), Área de Preservação Ambiental (APA) de Guaratuba e Reserva da Biosfera de Mata Atlântida (ReBIO).

A pesquisa-ação vem sendo conduzida desde 2006 na Zona de Educação para o Ecodesenvolvimento ${ }^{1}$. O programa propõe articulação entre ensino, pesquisa e extensão, envolvendo grupo interdisciplinar de pesquisadores que inclui estudantes do Programa de Pós-Graduação em Desenvolvimento Regional (mestrado e doutorado) com formação em Engenharia Florestal, Turismo, Economia, Sociologia, Geografia, Administração, Biologia, acadêmicos da graduação do Curso de Arquitetura da Universidade Regional de Blumenau (FURB), provenientes da iniciação científica, além de membros comunitários (ALCÂNTARA et al., 2014). Conta também com a colaboração do Programa de Pós-Graduação em Meio Ambiente e Desenvolvimento da Universidade Federal do Paraná - UFPR e do Programa de Honra em Estudos Interdisciplinares em Meio Ambiente e Desenvolvimento Sustentável da Universidade Austral de Chile, além de membros comunitários.

Uma dissertação de mestrado foi concluída em 2014, intitulada "Sistemas Agroflorestais: estratégia para o desenvolvimento territorial sustentável na Microbacia Hidrográfica do Rio Sagrado, zona rural de Morretes (PR)”, com a contribuição de construção de uma cartilha dirigida principalmente a agricultores, organizações de apoio comunitário e proprietários de áreas de preservação, e uma tese de doutorado está em curso, denominada "Projetos de desenvolvimento: processos de ensino-aprendizagem ou processos de instrumentalização? (ALCÂNTARA et al., 2015).

\footnotetext{
${ }^{1}$ [...] espaços em que se "privilegia o conhecimento, a compreensão, a proposição e o agir sobre o território de maneira que se conservem modos de vida tradicionais e se preserve a biodiversidade" (SAMPAIO et al., 2010, s. p.).
} 
O objetivo deste artigo está em analisar a contribuição do turismo de base comunitária na preservação da identidade cultural da Zona de Educação para o Ecodesenvolvimento na Microbacia Hidrográfica do Rio Sagrado, em Morretes, localizada na região Sudoeste do Estado do Paraná.

\section{TURISMO DE BASE COMUNITÁRIA E VALORIZAÇÃO DA CULTURA} LOCAL

Conforme Coriolano (2006), o turismo produz contradições quando se apresenta como promotor do desenvolvimento local, do cuidado com o lugar e na conservação de modos de vida. De um lado, transforma o espaço em mercadoria e massifica culturas; de outro, prima o atendimento das necessidades dos visitantes em detrimento das comunidades autóctones; e finalmente, enquanto negócio visa à obtenção de lucros e gera assimetrias na distribuição de riqueza.

Frente a este quadro e das mudanças na organização de trabalho no meio rural, estas comunidades buscaram um modelo de desenvolvimento que privilegiasse a conservação da cultura rural, mais solidária e inclusiva, e a preservação da biodiversidade, com manejo florestal e práticas agroecológicas (SAMPAIO; CARVALHO; ALMEIDA, 2007). Neste contexto, surgiu o turismo de base comunitária.

O turismo de base comunitária é uma estratégia de comunicação social para que comunidades tradicionais, com desvantagens históricas, viabilizem seus respectivos modos de vida (BARRETTO, 2004; GEERTZ, 2008). Neste sentido, mais do que uma modalidade de negócio é uma abordagem de desenvolvimento. Deste modo, faz-se necessário entender o turismo de base comunitária como:

[...] um subsistema interconectado a outros subsistemas, como educação, saúde e meio ambiente. Ou seja, o turismo de base comunitária é pensado como um projeto de desenvolvimento territorial sistêmico (sustentável), a partir da própria comunidade, o que poderia ser destacado como segunda característica. [...] A terceira característica é a convivencialidade, relação social que se interessa pelo outro, pelo diferente, alteridade, identidade, respeitando a simplicidade das comunidades tradicionais, suas rotinas, seu jeito de falar, cantar, dançar, comer, entre outros (SAMPAIO; ALVES; FALK, 2008, p. 254). 
Deste modo, a educação assume lugar de destaque, pois se constrói um conjunto de argumentos para tomada de consciência dos limites da sociedade de consumo (ARAÚJO; GELBCKE, 2008). Reconhece-se, no entanto, que a escala comunitária de desenvolvimento é insuficiente para garantir inserção socioeconômica, o que prescinde de políticas públicas e de economias em outras escalas, municipal, regional, estadual, nacional e internacional. Há, no entanto, que repensá-las para garantir que as economias populares possam sobreviver, sob uma lógica própria, enquanto alternativa de modos de vida, que, a priori, se apresentam mais ambientalmente sustentáveis.

Sob estes termos, Coriolano (2006), afirma que o turismo de base comunitária é uma estratégia de sobrevivência e de inserção de atores sociais com menos acesso as políticas públicas e as cadeias produtivas do turismo na economia de mercado. Mais do que uma modalidade de turismo, o turismo de base comunitária é uma visão de desenvolvimento, na qual privilegia o lugar, vizinhança, comunidade, modos de apropriação dos recursos naturais, ressignificando os modos de vida tradicionais como modos de vida dignos.

Entretanto, não se pode esquecer que a atividade de turismo acaba “[...] impactando com a região, seus meios de produção, pessoas e geografia. Num primeiro plano, a localidade necessita de uma prévia preparação para receber os consumidores do turismo: os turistas" (SILVA; MANTOVANELI JUNIOR; SAMPAIO, 2014, p. 164). Pacheco (2004, p. 136-137) coaduna com esta visão quando afirma que:

[...] é natural que se pense no turismo como alternativa ao desenvolvimento da região, mas isso deve ser pensado de forma a garantir sustentabilidade na utilização desse potencial. Os obstáculos ao turismo cultural e sustentável são notórios, a saber: tentativa de padronização da cultura, inferência da mídia sobre os hábitos locais, uma educação com tendência a transmissão das culturas dominantes, etc.

Neste sentido, Sampaio et al. (2006) propõe que o turismo de base comunitária se inspire nos mesmos princípios da ecossocioeconomia ${ }^{2}$, que tenta criar alternativas à hegemonia da racionalidade econômica. Neste sentido, aborda quatro dimensões:

\footnotetext{
${ }^{2}$ O termo ecossocioeconomia surge a partir da obra do economista ecológico Karl William Kapp (1963). O primeiro prefixo "Eco" (Oikos = Casa) refere-se à ecologia e reforça o sentido a que o segundo prefixo "eco" deveria remeter. Todavia, este foi vulgarizado ao longo da história ao remeter seu significado ao que Aristóteles já denunciava como crematística A ecossocioeconomia está imbricada na discussão sobre o ecodesenvolvimento, entendido como antecedente do desenvolvimento sustentável (SAMPAIO et al., 2010).
} 
valorização e preservação de tradições e relações sociais solidárias; geração de trabalho e renda por meio da produção associada ou socioempreendedora de atores ou unidades familiares; revigoramento dos significados de virtude humana e do próprio Estado distanciado do racionalismo utilitarista; e utilização apropriada dos recursos naturais e das capacidades humanas locais. Ou seja, um desenvolvimento à escala humana, protagonizado por Max-Neef (2012). Deste modo, as comunidades decidem que tamanho desejam ser, grandes ou pequenas e a economia serve as pessoas e não as pessoas à economia.

Assim, se fortalecem os arranjos socioprodutivos de base comunitária, valendose da lógica da economia de vizinhança, na qual se aproximam produtores e consumidores; e do comércio justo, que ainda firma acordos entre estes dois sujeitos. (GUZZATTI; SAMPAIO; CORIOLANO, 2013; GUZZATTI; TURNES; SAMPAIO, 2013). Ou como também sugere Sahlins (2003, p. 68), quando salienta que:

[...] a ordem cultural tem de ser concebida como a codificação da ação intencional e pragmática real do homem, ou se, ao contrário, a ação humana no mundo deve ser compreendida como mediada pelo projeto cultural, que ordena imediatamente a experiência prática, a prática ordinária, e o relacionamento entre as duas.

Neste contexto, o turismo de base comunitária proporciona uma prática de troca de experiências entre comunidade e visitantes, valorizando e vivenciando seus costumes, gastronomia, hábitos, cultura, símbolos, entre outros. Segundo Almeida (2007, p. 17):

\begin{abstract}
A valorização cultural da comunidade é parte importante no processo e sua preservação vai depender da evolução da atividade no local. Os ganhos e as evoluções que as comunidades têm são mensuradas com a melhoria cultural, benefícios em infraestrutura, crescimento educacional, econômico e aspectos que a comunidade julgue importante.
\end{abstract}

Como afirma Sachs (2007), este arranjo socioprodutivo pode contribuir para articular ou, ao menos, aproximar grupos de consumidores, grupos produtivos, empresas orientadas ao lucro, instâncias governamentais e demais organizações que convivem com a dialética de interesses da ecossocioeconomia, isto é, que promove o desenvolvimento à escala humana, no qual se realiza no plano concreto e não apenas no plano ideológico, socialmente includente e ambientalmente prudente. 


\section{IDENTIDADE CULTURAL}

A identidade cultural é compreendida como culturalmente formada e, por sua vez, “[...] está ligada à discussão das identidades coletivas, como as identidades regionais, nacionais e outras que constituem quadros de referência e sentidos estáveis, contínuos e imutáveis por sob as divisões cambiantes e as vicissitudes de uma história real" (HALL, 1996, p. 68). Por sua vez, a cultura engloba todas as formas de expressão do homem: sentir, agir, pensar, fazer, bem como as relações entre os seres humanos e destes com o meio ambiente. De acordo com Andrade (1987, p. 21):

\footnotetext{
Aquilo que se denomina Patrimônio Histórico e Artístico Nacional [...] é o documento de identidade da nação brasileira. A subsistência desse patrimônio é que comprova, melhor do que qualquer outra coisa, nosso direito de propriedade sobre o território que habitamos.
}

Para Oliveira (2015), a identidade cultural como um sistema de representação das relações entre indivíduos e grupos, envolve o compartilhamento de patrimônios comuns como língua, religião, artes, trabalho, esportes, festas, entre outros. Ou seja, é um processo dinâmico de construção continuada que se alimenta de várias fontes no tempo e no espaço, tendo seu viés a preservação do patrimônio local com suas características e peculiaridades. Surge como a valorização do turismo, lazer e qualidade de vida dos indivíduos.

Assim, o que se busca por meio do turismo de base comunitária é a autenticidade da identidade cultural inerente a cada sujeito. Pois quando se reúne aos aspectos das sociedades humanas que são aprendidos e não herdados, reporta-se à definição de que: "Esses elementos da cultura são partilhados pelos membros da sociedade e tornam possível a cooperação e a comunicação. Eles formam o contexto comum em que os indivíduos de uma sociedade vivem as suas vidas" (GIDDENS, 2004, p. 22). Conforme o autor, a cultura engloba tanto os aspectos intangíveis - crenças, ideias e valores que constituem o teor da cultura - como os aspectos tangíveis - objetos, símbolos ou a tecnologia que representa esse conteúdo.

A produção (reprodução) da cultura, para Durham (2004), depende de um instrumental simbólico que é cristalizado nos mitos, regras explícitas, teorias que os homens constroem para explicar a natureza, sociedade e seu próprio destino, e que 
podem ser concebidos como "objetos culturais", produzidos socialmente. A autora defende, ainda, a preservação do conceito de cultura como instrumento para analisar a questão do simbolismo e da significação na ação humana.

Este instrumento simbólico pode ser representado pelo turismo de base comunitária, na concepção do turismo cultural que "[...] compreende as atividades turísticas relacionadas à vivência do conjunto de elementos significativos do patrimônio histórico e cultural e dos eventos culturais, valorizando e promovendo os bens materiais e imateriais da cultura" (BRASIL, 2010a).

Brandão (1986, p. 3), afirma que: “[...] a identidade se constitui como uma categoria de atribuição de significados específicos a tipos de pessoas em relação umas com as outras e, em nosso caso específico, aqui, em relações interétnicas [...]”. Para Brandão (1986, p. 77) a identidade atua:

[...] como processo (identificação) e produto (identidade) de um trabalho cultural de grupos sociais, que resulta na descrição de significados de diferenciação social, étnica, etc. Identidades podem ser geradas, preservadas, extintas, transformadas, dependendo não tanto de uma voluntária vontade simbólica do grupo, mas das atribulações pelas quais passa na realização cotidiana de sua própria história. Atribulações que, nos casos descritos aqui como base aos que serão descritos a seguir, vão da defesa de um território físico, político de assentamento, vida e trabalho do grupo, até a autoatribuição de um lugar simbólico do grupo, no território de nomes e significados com que ele se localiza entre outros.

Cada cultura possui uma configuração particular específica e, portanto, única, como cada povo, que pode compartilhar elementos culturais com outros povos vizinhos em função de um processo imitativo e de contato através do tempo. Sauer (1998), com uma visão mais particularista, adapta esta noção de "áreas/paisagens culturais", com povos que possuem estilos de vida próprios baseados em história local. Hall (1996, p. 70) define as identidades culturais como:

\footnotetext{
Pontos de identificação, os pontos instáveis de identificação ou sutura, feitos no interior dos discursos da cultura e história. Não uma essência, mas um posicionamento. Donde haver sempre uma política da identidade, uma política de posição, que não conta com nenhuma garantia absoluta numa lei de origem "sem problemas", transcendental.
}

Neste sentido, defende-se a preservação do conceito de cultura como instrumento para analisar a questão do simbolismo e da significação na ação humana. 


\section{RESULTADOS E DISCUSSÕES: TURISMO DE BASE COMUNITÁRIA NA ZONA DE EDUCAÇÃO PARA O ECODESENVOLVIMENTO}

Experiências de turismo de base comunitária chamam a atenção pela capacidade de desenvolver atividades econômicas de baixo investimento, gerando postos de trabalho de baixo impacto ambiental, preservando ao mesmo tempo, a cultura e identidade de um lugar. Entretanto, são poucas as comunidades que demonstram esta capacidade. Um exemplo de sucesso deste tipo de arranjo socioprodutivo de base comunitária é a Zona de Educação para o Ecodesenvolvimento do Rio Sagrado, localizada no Município de Morretes, região sudoeste do Estado do Paraná à $68 \mathrm{~km}$ da capital Curitiba (MANSUR et al., 2013) (Figura 1).

Figura 1 - Mapa de Localização da Microbacia Hidrográfica do Rio Sagrado, Morretes (PR) e Mapa de Comunidades da Microbacia.

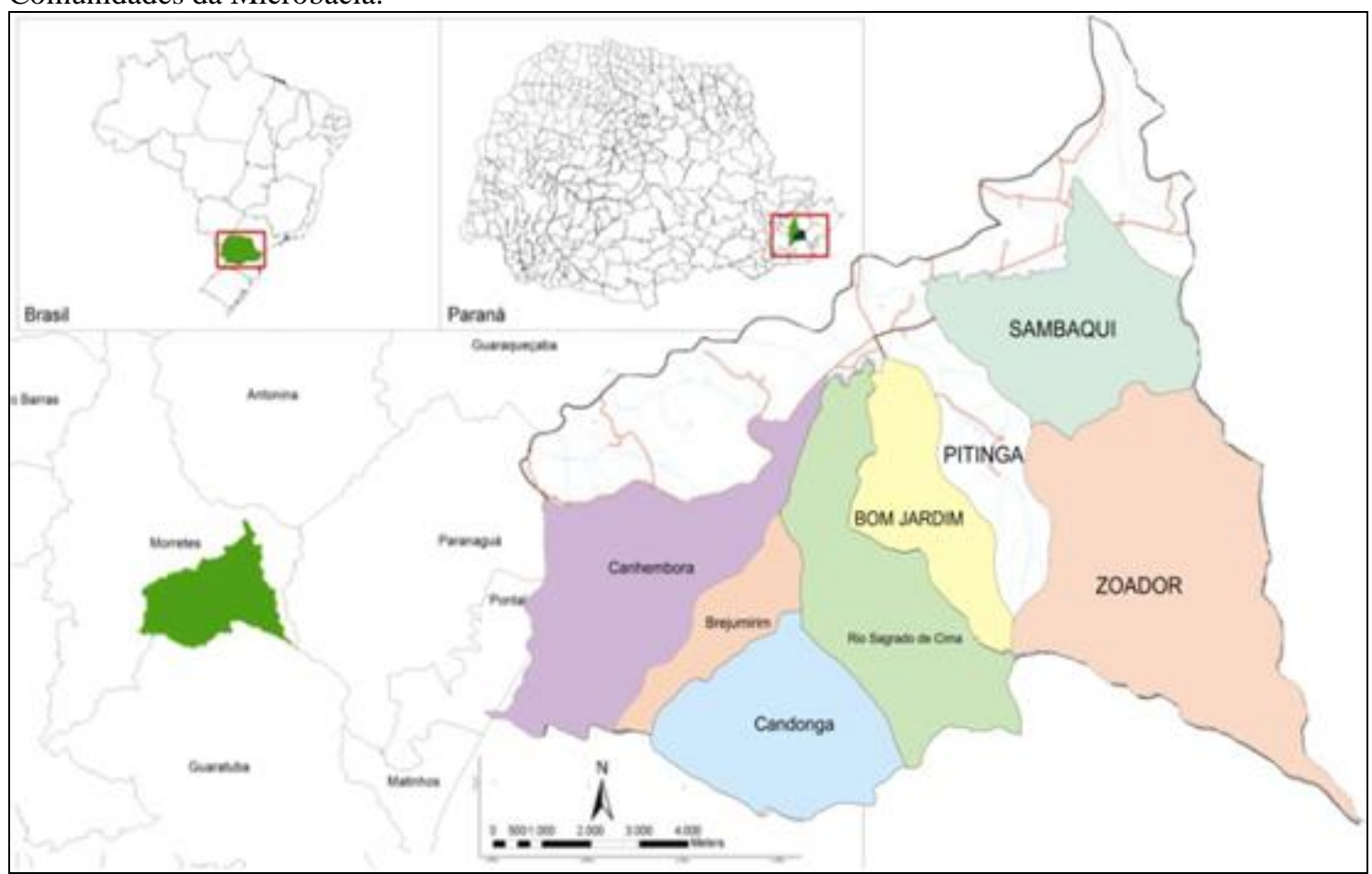

Fonte: Adaptado de Feuser (2010); Braguirolli (2010); Mansur et al. (2011).

O estudo realizado por pesquisadores de 2006 a 2012 no âmbito do projeto de Intervivência Universitária, intitulado "Programa de Honra de Estudos e Práticas de 
Ecossocioeconomia $^{3 "}$ trouxe à tona aspectos históricos e socioeconômicos da localidade. De acordo com Feuser e Santos (2011), moradores mais antigos de Rio Sagrado relataram que os primeiros a chegarem à localidade foram trabalhadores da empresa de telégrafos, que prestavam serviços de manutenção de linhas, com destaque para poda de árvores de maneira que os fios não fossem danificados.

Conforme Henriquez e Tomazelli (2006), por volta de 1870, não havia exploração da biodiversidade para atividades produtivas de comércio. Logo, algumas famílias alemãs migraram para a localidade, explorando terras por meio da agricultura e comercializando os excedentes produzidos. De acordo com os autores, foi nesta fase que se iniciaram os danos ambientais, principalmente pela substituição de mata nativa por monocultura, além de posterior extração de madeira, dando início à abertura de estradas.

Constatou-se que a comunidade do Rio Sagrado compõe-se por pequenas propriedades rurais com agricultura de subsistência. A ausência de perspectivas econômicas contribuiu para o fortalecimento do êxodo rural, sobretudo entre os jovens, em busca de trabalho nas grandes cidades. Esta realidade mudou com a perspectiva da chegada do turismo comunitário, fortalecida com a possibilidade das vivências comunitárias.

Deste modo, na Zona de Educação se estabeleceu uma rede de esforços caracterizada como arranjo socioprodutivo de base comunitária, iniciada a partir de um projeto-piloto chamado Montanha Beija-Flor Dourado, envolvendo inicialmente quatro famílias, chefiadas predominantemente por mulheres, que assumiram a tarefa de se autofinanciarem para pensar uma proposta de turismo de base comunitária, formando uma cadeia socioprodutiva (SAMPAIO; CARVALHO: ALMEIDA, 2007).

Entre os serviços oferecidos destacavam-se: hospedagem, alimentação caseira, manutenção predial, limpeza, oficinas de artesanato, guia de trilhas e visitação em propriedades que adotavam a agroecologia - e uma rede sociopolítica, contando com a coordenação conjunta da Universidade Regional de Blumenau e Universidade Federal do Paraná (SAMPAIO; ZECHNER; HENRIQUEZ, 2008, p. 12).

\footnotetext{
${ }^{3}$ O Programa de Honra foi financiado pelo Edital 23/2008 pelo Conselho Nacional de Desenvolvimento Científico e Tecnológico (CNPq)/Ministério da Ciência e Tecnologia (MCT) e Fundo Setorial do Agronegócio (CT-Agronegócio)/Ministério do Desenvolvimento Agrário (MDA), encampado pela Universidade Regional de Blumenau (FURB) e Universidade Federal do Paraná (UFPR).
} 
O projeto de pesquisa-ação identificou que a pluriatividade estava tendo espaço na organização produtiva local, sendo que os principais produtos cultivados eram a mandioca e a banana. Ambos caracterizando-se como insumos de agroindustrialização, como: fabricação de sorvete, confecção de artesanato e farinha de mandioca para comercialização. Grande parte dos moradores estava dividida em tarefas agrícolas e pecuárias em suas propriedades e a prestação de serviços ou trabalho remunerado por terceiros. Os cultivos realizados na área se constituíam de banana, palmito-pupunha, café, mandioca, pimentão, abóbora, feijão, entre outros.

Verificou-se que o escoamento da produção, bem como formas de comercialização provenientes do território encontravam dificuldades. O comércio local se restringindo a bares, dois mercados que vendiam insumos de primeira necessidade, uma loja de roupas, duas pousadas, uma chácara com venda de plantas ornamentais e uma propriedade em que se vendia sorvete fabricado na localidade. Para Grimm (2010), a aquisição de bens necessários (como medicamentos, por exemplo) era dependente do centro urbano de Morretes.

As comunidades de Rio Sagrado de Cima, Canhembora, Brejumirim e Candonga estavam organizadas em duas associações: a Associação de Moradores de Rio Sagrado (AMORISA), criada com o intuito de auxiliar na gestão do abastecimento de água, mas que também atuava em frentes de organização comunitária com outras finalidades; e a Associação Comunitária Candonga, conhecida como "Cozinha Comunitária", cujas instalações abrigavam equipamentos de agroindustrialização de insumos in natura, produzidos no território (ALVES, 2008).

Neste sentido, a Zona de Educação do Rio Sagrado estava promovendo um arranjo socioprodutivo local, cuja propulsão residia no desenvolvimento do turismo de base comunitária. Observou-se que, entre as atividades de turismo de base comunitária que estavam acontecendo na região analisada, havia desde observação de pássaros e trilhas ecológicas à participação dos turistas no processo artesanal de fabricação da farinha de mandioca, artesanato, visitação a propriedades agroecológicas, feiras de trocas solidárias e outros. Os visitantes se hospedavam em uma pousada local que utilizava de produção orgânica e participavam de vivências a partir dos modos de vida, produção e conhecimento da comunidade. 
Uma das vivências na comunidade acontecia na fabricação da farinha de mandioca, que estava sendo feita de forma tradicional em um engenho que contava com mais de 150 anos. Os equipamentos do engenho foram produzidos com madeira da região, com exceção do forno de cerâmica. A única fonte de inovação do engenho era um ralador elétrico, substituindo o moinho de água utilizado antigamente. Os visitantes acompanhavam todo o processo de produção, podendo saborear a gastronomia local. A mesma dinâmica estava ocorrendo na fabricação do artesanato com cipó, onde os visitantes participavam do processo de fabricação de vários artefatos produzidos de forma artesanal.

Para Grimm (2010), o objetivo das vivências práticas era de enfrentamento de limitações ocasionadas por fatores como isolamento e dificuldades de acesso, de maneira que assegurasse a sobrevivência socioeconômica da população, conservando a biodiversidade local e os modos de vida. Deste modo, as vivências do turismo de base comunitária proporcionaram a oportunidade de troca de experiências entre membros das comunidades e visitantes, como tentativa de valorizar a cultura e a identidade local.

Neste contexto, se verificou que a localidade possuía potencial para o turismo de base comunitária, justificado pela troca dos saberes comunitários com turistas e visitantes. Como afirmam Freire e Pereira (2005), essas vivências na natureza podem gerar nas pessoas uma tomada de consciência quanto a valores, relações sociais e respeito com a natureza, pelos ciclos biológicos, ao invés do domínio sobre ela. Neste sentido, se preservou a identidade cultural da comunidade em questão por meio de estratégias de turismo comunitário.

\section{CONCLUSÕES}

A partir do objetivo de pesquisa em que se buscava identificar a importância do turismo de base comunitária para a preservação da identidade local da Zona de Educação para o Ecodesenvolvimento na Microbacia Hidrográfica do Rio Sagrado, concluiu-se que o turismo de base comunitária estava se mantendo como proposta institucional: conservando modos de vida tradicionais e preservando a biodiversidade local, ou seja, garantindo a sociobiodiversidade e identidade territorial. 
Constatou-se que além de pressupor relações fortalecidas, baseadas na convivência e na troca entre a comunidade e os visitantes, contribuiu na preservação da identidade cultural, do patrimônio e do modo de vida. Ou seja, tornou-se uma alternativa possível, cooperando para que a lógica comunitária de experiência de turismo na comunidade de Rio Sagrado não perdesse sua dinâmica natural.

Este modelo de arranjo voltado ao turismo de base comunitária, que oportunizava a aproximação do visitante com os moradores da comunidade, surgiu como uma alternativa de conservação não somente da identidade do local e da preservação do patrimônio, mas da biodiversidade, partindo de suas peculiaridades. Recorda-se Geertz (2008), que a cultura não está dentro nem funciona por meio dos seres humanos, mas é constantemente reproduzida por eles. Entende-se que na comunidade em questão, a reprodução estava ocorrendo por meio do turismo de base comunitária, interpretação, leituras, signos, processo de ensino e aprendizado, momentos de troca e vivência comunitária.

Não se verificou estar sendo explorada ainda, a potencialidade dos serviços ambientais, por considerar que está situado em Área de Proteção Ambiental, exigindo grandes esforços dos agricultores e demais moradores para cumprirem a legislação quanto a adaptação de seus modos de produção e suas restrições. Neste sentido, conhecer as necessidades e potencialidades da comunidade é imprescindível para este modelo de arranjo.

Além disso, percebeu-se que o maior desafio consistia na mobilização da comunidade na construção de um modelo em constante transformação, considerando a interdisciplinaridade e a complexidade dos sistemas sociais, políticos, econômicos, ambientais e culturais, mobilizando competências, saberes e conhecimento. Deste modo, o território do Rio Sagrado representa o lócus dos sistemas de representações, identidades, símbolos e mitos que as populações tradicionais constroem, pois é com base nele que agem sobre o meio ambiente em que vivem.

Ao mesmo tempo, para que continue a ser viável, sugere-se que políticas públicas de turismo de base comunitária surjam das demandas de populações locais, de quem nasce, cresce, vive e morre no seu território base, prerrogativa de um enfoque de educação surgida a partir da instrumentalização da atividade turística. Lembrando que, 
antes que o turismo possibilite qualidade de vida ao visitante, ele primeiro deve possibilitar bem estar comum e garantir a sobrevivência de seus membros.

\section{REFERÊNCIAS}

ALCÂNTARA, L. C. S.; SOUZA, C. M. M. S.; SAMPAIO, C. A. C.; GRIMM, I. J.; GESER, J. H. Conhecimento e ação territorial: a interdisciplinaridade em zonas de educação para o ecodesenvolvimento. In: Interdisciplinaridade e Ambiente. Maranhão: EDUFMA, 2014.

ALCÂNTARA, L. C. S.; PEllin, V.; SAMPAIO, C. A. C.; SOUZA, C. M. M. S. Zona de educação para o ecodesenvolvimento: aproximação da universidade com a comunidade. In: Revista Desenvolvimento e Meio Ambiente, v. 33, p. 129-147, abr. 2015. Disponível em:

<http://ojs.c3sl.ufpr.br/ojs2/index.php/made/issue/current/showToc〉.

ALMEIDA, N. de P. Segmentação do turismo no pantanal brasileiro. Campo Grande, MS: ED UFMS, 2007.

ALVES, F. K. Arranjo socioprodutivo de base comunitária (APL.Com): um projeto piloto na comunidade do entorno da Microbacia do Rio Sagrado (Morretes, PR). Dissertação (Mestrado em Administração). Universidade Regional de Blumenau, 2008.

ANDRADE, R. M. F. de. Rodrigo e o SPHAN: coletânea de textos sobre o patrimônio cultural. Rio de Janeiro: Fundação Nacional Pró-Memória: 21, 1987.

ARAÚJO, G. P. de; GELBCKE, D. L. Turismo comunitário: uma perspectiva ética e educativa de desenvolvimento. Revista Turismo Visão e Ação - Eletrônica, v. 10, n. 3, p. 357-378, set./dez./2008.

BARRETTO, M. Relações entre visitantes e visitados: um retrospecto dos estudos socioantropológicos. Turismo em Análise, v. 15, n. 2, p. 133-149, novembro de 2004.

BRANDÃO, C. R. Identidade e etnia: construção da pessoa e resistência cultural. São Paulo: Brasiliense, 1986, 173 p.

BRAGHIROLLI, G. Análise dos fatores físico-naturais da comunidade Brejumirim, Microbacia Hidrográfica do Rio Sagrado. In: $4^{\text {a }}$ MOSTRA INTEGRADA DE ENSINO, PESQUISA E EXTENSÃO - MIPE. Blumenau: FURB, 2010.

BRASIL, Ministério do Turismo. Segmentação do Turismo: marcos conceituais. Brasília: Ministério do Turismo, 2010a. 
BRASIL. Ministério do Turismo. Turismo rural: orientações básicas. / Ministério do Turismo, Secretaria Nacional de Políticas de Turismo, Departamento de Estruturação, Articulação e Ordenamento Turístico, Coordenação Geral de Segmentação. 2. ed. Brasília: Ministério do Turismo, 2010b.

CORIOLANO, L. N. M. T. Turismo: prática social de apropriação e de dominação de territórios. Publicación: América Latina: cidade, campo e turismo. In: LEMOS, A. I. G. de; ARROYO, M.; SILVEIRA, M. L. (Orgs). CLACSO, Consejo Latinoamericano de Ciencias Sociales, San Pablo. Diciembre, 2006. Disponível em: $<$ http://biblioteca.clacso.edu.ar/ar/libros/edicion/lemos/21 coriol.pdf >.

DURHAM, E. R. Cultura e ideologia. In: O. R. T. (Org). A dinâmica da cultura: ensaios de antropologia. São Paulo, Editora CosacNaify: 2004, p. 255-280.

FEUSER, S. Análise dos fatores físico-naturais da comunidade Rio Sagrado de Cima, Microbacia Hidrográfica do Rio Sagrado. In: 4. MOSTRA INTEGRADA DE ENSINO, PESQUISA E EXTENSÃO - MIPE. Blumenau: FURB, 2010.

FEUSER, S.; SANTOS, G. F. dos. Processo histórico da ocupação humana e do uso dos recursos naturais na microbacia hidrográfica do Rio Sagrado (Morretes, PR): zona de educação para o ecodesenvolvimento. Relatório de Iniciação Científica. Blumenau: FURB, 2011.

FREIRE J. B.; PEREIRA V. B. C. Percepções e significados nas caminhadas ecológicas. 2005. Disponível em: <http://www.efdeportes.com/efd80/caminha.htm>. Buenos Aires, Revista Digital. Acesso em: Julho de 2014.

GEERTZ, C. A interpretação das culturas. 1. ed. 13. reimpr. Rio de Janeiro: LTC: 2008.

GIDDENS, A. Sociologia. 4. ed. Revista e atualizada. Lisboa: Fundação Calouste Gulbenkian, 2004.

GRIMM I. J. Planejamento territorial: uma metodologia de monitoramento de indicadores socioambientais na microbacia hidrográfica do Rio Sagrado, Morretes (PR). Dissertação (Mestrado em Desenvolvimento Regional) - Fundação Universidade Regional de Blumenau, 2010.

GUZZATI, T. C.; SAMPAIO, C. A. C.; CORIOLANO, L. N. M. T. Turismo de base comunitária em territórios rurais: caso da Associação de Agroturismo Acolhida na Colônia (SC). Revista Brasileira de Ecoturismo, v. 6, 2013, p. 93-106.

GUZZATI, T. C.; TURNES, V. A.; SAMPAIO, C. A. C. Nuevas relaciones entre agricultores familiares y consumidores: perspectivas recientes en Brasil y en Francia. In: III CONGRESSO INTERNACIONAL DE DESENVOLVIMENTO LOCAL, 2013, Havana (Cuba). Anale..... Universidad de la Havana: Havana, 2013. 
KAPP, K. W. The social costs of business enterprise. Nottingham: Spokesman Books, 1963. Não encontrada no texto.

HALL, S. Identidade cultural e diáspora. In: Revista do Patrimônio Histórico e Artístico Nacional. Rio de Janeiro, IPHAN, 1996.

HENRIQUEZ, C. Z.; TOMASELLI, T. Formulário qualitativo. Coleta de dados da disciplina Planejamento Ambiental de Empresas de Turismo e Lazer, ministrados pelo Prof. Dr. Carlos Alberto Cioce Sampaio e a estagiária docente Márcia Silveira de Souza em 2006, do Curso de Graduação em Turismo e Lazer da Universidade Regional de Blumenau (FURB), 2006.

MANSUR, C. de M. S.; AUMOND, J. J.; SANTOS, G. F. dos; WAGNER, O. V.; DOURADO, E. C.; FEUSER, S.; ANDRADE, A. B.; ANDRADE, A.; BRAUN, S.; HOLLER, L.; DUWE, S. Projeto de extensão rural: monitoramento de indicadores socioambientais para a gestão territorial participativa da Microbacia do Rio Sagrado, ZEE. Relatório Final de Projeto de Extensão. Blumenau: FURB, 2011.

MANSUR, C. de M. S.; PILAN, J;, SANTOS, G. F.; AUMOND, J. J.; BRAUN, S.; FUSÃO, L. Análise ambiental dos fatores físico-naturais: zoador, microbacia hidrográfica do Rio Sagrado, Morretes (PR), Brasil. ANAIS (2013). Disponível em: $<$ http://www.egal2013.pe/wp-content/uploads/2013/07/Tra_Cristiane-Juliana-GilbertoJuares-Samara-Luciana.pdf $>$. Acesso em: maio de 2015.

MAX-NEEF, M. Desenvolvimento à escala humana. Blumenau: Edifurb, 2012.

OLIVEIRA, L. M. B. Identidade cultural. Dicionário de Direitos Humanos. Disponível em:

<http://www.esmpu.gov.br/dicionario/tiki-index.php?page=Identidade+cultural >. Acesso em: julho de 2015.

PACHECO, I. M. de J. O imaginário da carta de Caminha e sua apropriação pelo turismo. Dissertação (mestrado em Cultura e Turismo) - Universidade Estadual de Santa Cruz UESC e Universidade Federal da Bahia UFBA. Ilhéus (BA): 2004.

SACHS, I. Rumo à ecossocioeconomia: teoria e prática do desenvolvimento. São Paulo: Cortez, 2007.

SAHLINS, M. Cultura e razão prática: dois paradigmas da teoria antropológica. In: Cultura e razão prática. 1. ed. Rio de Janeiro: Zahar Editora, 2003.

SAMPAIO, C. A. C.; OYARZÙN E; SOUZA, M. S. de.; CÁRCAMO, C.; MANTOVANELI JÚNIOR, O. Arranjo socioprodutivo de base comunitária: análise comparativa de experiências de turismo comunitário no Brasil e no Chile. In: IV SEMINÁRIO DE PESQUISA EM TURISMO DO MERCOSUL. Caxias do Sul, 7 e 8 de julho de 2006. 
SAMPAIO, C. A. C.; CARVALHO, M. B.; ALMEIDA, F. H. R. Turismo comunitário: projeto piloto montanha beija-flor dourado (Microbacia do Rio Sagrado, Morretes, Paraná). Turismo - Visão e Ação, v. 9, n. 2, p. 249-266 maio /ago. 2007.

SAMPAIO, C. A. C.; ALVES, F. K.; FALK, V. C. V.; Arranjo socioprodutivo de base comunitária: interconectando o turismo comunitário com redes de comércio justo. In: Turismo Revista Turismo Visão e Ação - Eletrônica, v. 10, n. 2, Mai./Ago./2008, p. 244-262.

SAMPAIO, C. A. C.; ZECHNER, T. C.; HENRIQUEZ, C. Z. Pensando o conceito de turismo comunitário a partir de experiências brasileiras e chilenas vividas. Blumenau: FURB, 2008.

SAMPAIO, C. A. C.; ARAUJO, J. R.; DIAS, A.; ZUNIGA, C. E. H.; SOUZA, C. M. M. Educación para el ecodesarrollo: micro-cuenca del Río Sagrado. In: CONGRESSO CHILENO DE ANTROPOLOGIA, 2010, Valdivia. Congresso Chileno de Antropologia, 2010.

SAUER, C. O. A morfologia da paisagem. In: CORRÊA, R. L.; ROSENDAHL, Z. (orgs.). Paisagem, tempo e cultura. Rio de Janeiro: EdUERJ: 1998, p. 12-74.

SILVA, L. F. da; MANTOVANELI JÚNIOR, O.; SAMPAIO, C.A.C. Desenvolvimento turístico regional: governança e territorialidade no caso da Oktoberfest Blumenau (Santa Catarina, Brasil). Turismo e Sociedade. Curitiba, v. 7, n. 1, p. 156-173, janeiro de 2014.

THOMPSON, J. B. Ideologia e cultura moderna: teoria social crítica na era dos meios de comunicação de massa. Rio de Janeiro: Vozes, 1995.

Recebido em: 09-01-2015.

Aprovado em: 08-02-2015. 